\title{
Ability of parents to recall the injuries of their young children
}

\author{
P Cummings, F P Rivara, R S Thompson, R J Reid
}

Injury Prevention 2005;11:43-47. doi: 10.1136/ip.2004.006833

See end of article for authors' affiliations

.......................

Correspondence to:

Dr Peter Cummings, 250

Grandview Drive, Bishop

CA 93514, USA; peterc@

u.washington.edu
Objective: To estimate the ability of parents to recall the injuries of their children.

Design: Comparison of parent recall with computerized medical records.

Setting: A health maintenance organization in Washington State during 2003.

Subjects: Parents of children younger than 6 years.

Main outcome measures: The ratio of recalled injuries to injuries in computerized data.

Results: Telephone interviews were completed with a parent of 1672 young children who had computerized medical data for at least one injury in the last year. Counting the three most recent treated injuries, the 1672 children had 1896 separate new injuries in the year before interview and parents recalled 1150 of these: recall ratio 0.61 (95\% confidence interval (CI) 0.58 to 0.63 ). The recall ratio decreased from $0.82(95 \% \mathrm{Cl} 0.79$ to 0.85$)$ for injuries one day before interview to $0.37(95 \% \mathrm{Cl} 0.32$ to 0.40 ) at 365 days before interview. For 341 major injuries the recall ratio was $0.80195 \% \mathrm{Cl} 0.76$ to 0.84), for 202 minor injuries treated in an emergency department or hospital it was 0.77 (95\% $\mathrm{Cl} 0.71$ to 0.82), for 597 minor injuries treated in urgent care it was 0.70 ( $95 \% \mathrm{Cl} 0.65$ to 0.73$)$, and for 756 minor injuries treated in a clinic it was $0.43(95 \% \mathrm{Cl} 0.39$ to 0.47$)$.

Conclusions: Recall decreased with time. Recall was best for major injuries, intermediate for minor injuries treated in a hospital, emergency department, or urgent care center, and worst for minor injuries treated in a clinic. in some studies it may be useful to ask parents to recall the injuries of their children. The National Children's Study is being planned with the goal of following 100000 children from birth to age 21 years. ${ }^{1}$ In that study parents will be asked periodically about the health of their children. Estimates of injury occurrence may be biased if recall is not accurate. Estimates of association between an exposure and injuries may be biased if recall varies with time since injury or with other factors.

To study the ability of parents to recall the injuries of their children younger than 6 years, we sampled children who had computerized information for a medical visit for a new injury within the last year. A parent was interviewed by telephone and asked about the child's medical visits for injuries in the last year. We estimated how recall of treated injuries varied by time since the injury and other factors.

\section{SUBJECTS AND METHODS}

\section{Study population}

We studied members of Group Health Cooperative, a nonprofit health maintenance organization in Washington. Nearly all medical care utilization can be tracked in computerized records. Even if members use services outside of Group Health, information from submitted bills is entered into computerized data.

\section{Study sampling criteria}

Children were randomly sampled from Group Health computerized utilization data if they: (1) were Group Health members for at least a year or since birth; (2) were members when sampled; (3) were alive; (4) had medical care for an injury in the 365 days before sampling; (5) were younger than 5 years plus 340 days, so they would be younger than 6 years when the parent was interviewed. An injury was defined as a diagnosis code from the International Classification of Diseases, 9th revision, clinical modification ${ }^{2}$ in one of the following ranges: (1) 800-904; (2) 910-929; (3) 940-957. External cause of injury codes were not used to select records.

\section{Survey questions}

For each selected child, our goal was to interview the parent or other adult caregiver and ask them to recall all new injuries in the past year that involved a medical visit. Injury was defined as cuts, punctures, scrapes, bruises, fractures, burns, but not poisonings. Caregivers were asked about the date of the three most recent treated injuries.

\section{Participation}

A letter was sent to tell parents about the study and allow them to decline further contact. After 10 days, attempts were made to reach the parents by telephone. Up to 12 calls were made over 14 days.

Starting in February 2003, children were randomly sampled weekly without replacement for 21 weeks. For the last three weeks we sampled all children who were still eligible. Interviews stopped on August 11.

Of 2807 children sampled, interviews were not completed because of sampling errors (85), death (1), serious illness (1), language barriers (45), refusals (494), the family was located but never completed the interview (188), the family could not be located (185), and the interviewing window had passed (12). There were 1796 completed interviews, $66 \%$ of all subjects who were or may have been eligible. ${ }^{3}$

Interviewed parents gave us verbal consent. Study procedures were approved by the Human Subjects Review Committee of the Group Health Cooperative Center for Health Studies.

\section{Definition of a new injury}

Each child's computerized records were sorted by visit date for the two years before parent interview. For each visit we identified the first diagnosis code that fit our injury definition; records may have 15 codes. We considered a visit to not be for a new injury if (1) a code was present for late effects of injury (905-909); (2) a code indicated aftercare (V50-V59); (3) the time from the previous visit was less than 41 days and the first injury code had the same first three 
digits on both visits; or (4) the time from the previous visit with any injury code was less than 10 days. If the time between injury visits was shorter than 41 days, we reviewed all the injury codes by date and made further decisions. For example, if a child had a code for a sprained ankle, and returned three days later with a code for a fractured ankle, we considered these to represent the same injury.

There were 45 children with diagnosis code 839 for other and ill defined dislocations. Most codes had fourth digits for spinal dislocations and were from chiropractor visits. We felt these were not likely to represent new injuries and visits were not considered injury related solely for this code.

Our new injury definition eliminated 124 children with interviews, leaving 1672 children with interviews and utilization data for at least one new injury in the previous 365 days.

\section{Variables that might affect recall}

We wished to know if recall might be related to child age, child sex, age of interviewed adult, number of children in the home, household income, and education of the interviewed adult. We did not ask about the sex of the respondent. For analyses we categorized treatment place in a hierarchy from highest service intensity to lowest: emergency department or hospital, urgent care, primary care clinic. If a child went to more than one of these for the same injury, that injury was assigned to the highest level used by that child.

Injury type was categorized in a hierarchy from highest level of seriousness to lowest: (1) brain and internal injuries (codes 800-829); (2) fractures and dislocations (codes 800829, 830-831, 833-838); (3) burns (codes 940-949); (4) open wounds (codes 870-897); (5) bruises and crushing (codes 910-929, 950-959); (6) sprains, including radial head subluxation (codes 831,840-848). The first injury diagnosis code was used to categorize injuries. If this code varied between visits the injury was assigned to the highest category. For analyses of recall by injury type, we collapsed these groups into major injuries (groups 1-3) and minor injuries (groups 4-6).

\section{Statistical analysis}

We estimated the proportion of new child injuries with a medical visit in the past year that could be recalled by an adult. Logistic regression was used to estimate the change in this proportion with time. ${ }^{4}$ This analysis used the time to each of the three most recent new injuries in the year before interview; only four children had more than three separate new injuries in the visit data and only two parents reported a child with more than three new injuries. We used main effects terms and interaction terms to test whether the proportion of injuries recalled varied by other factors; models with additional terms were compared with reduced models using the likelihood ratio test, the Hosmer-Lemeshow test, ${ }^{4}$ and Akaike's Information Criteria. ${ }^{5}$ Fractional polynomials and generalized additive models were used to search for evidence that a line other than linear on the log odds scale produced a better fit to the data ${ }^{6-8}$; we found no such evidence.

The count of the three most recent reported injuries in the previous 365 days was divided by the count of the most recent three new injuries in the computerized data; we used exact Poisson confidence intervals (CIs) for this rate ratio.

For respondents who recalled up to three injuries, we used a paired $t$ test to compare ( 1 ) the days from the interview to the injury date reported by the parent with (2) the days from interview to the first visit for that injury in the utilization data. For $56 \%$ of recalled injuries, adults could report the month and year, but not the day; for those records we assigned the day of the month as the 15th, resulting in a
Table 1 Characteristics of 1672 study children with a record of an injury in the previous year, adult respondents, and households

\begin{tabular}{|c|c|c|c|}
\hline & $\begin{array}{l}\text { Total }(n=1672 \text { ) } \\
\text { No (column \%) }\end{array}$ & $\begin{array}{l}\text { Respondent } \\
\text { did not recall } \\
\text { injury } \\
(n=579) \\
\text { No (row \%) }\end{array}$ & $\begin{array}{l}\text { Respondent } \\
\text { did recall } \\
\text { injury } \\
\text { ( } n=1093 \text { ) } \\
\text { No (row \%) }\end{array}$ \\
\hline \multicolumn{4}{|l|}{ Child age (years) } \\
\hline$<1$ & $63(4)$ & $30(48)$ & $33(52)$ \\
\hline $1-<2$ & $239(14)$ & $78(33)$ & $161(67)$ \\
\hline $2-<3$ & $372(22)$ & $116(31)$ & $256(69)$ \\
\hline $3-<4$ & $347(21)$ & $128(37)$ & $219(63)$ \\
\hline $4-<5$ & $343(21)$ & $127(37)$ & $216(63)$ \\
\hline $5-<6$ & $308(18)$ & $100(32)$ & $208(68)$ \\
\hline \multicolumn{4}{|l|}{ Child sex } \\
\hline Female & $736(44)$ & $258(35)$ & $478(65)$ \\
\hline Male & $936(56)$ & $321(34)$ & $615(66)$ \\
\hline \multicolumn{4}{|c|}{ Respondent's age (years) } \\
\hline $18-30$ & $497(30)$ & $179(36)$ & $318(64)$ \\
\hline $31-40$ & $913(55)$ & $301(33)$ & $612(67)$ \\
\hline $41-67$ & $256(15)$ & 99 (39) & $157(61)$ \\
\hline \multicolumn{4}{|l|}{$\begin{array}{l}\text { Respondent's relationship } \\
\text { to child }\end{array}$} \\
\hline Birth parent & $1615(97)$ & $557(34)$ & $1058(66)$ \\
\hline Other & $56(3)$ & 22 (39) & 34 (61) \\
\hline \multicolumn{4}{|l|}{ Respondent's education } \\
\hline High school or less & $235(14)$ & $89(38)$ & $146(62)$ \\
\hline Some college & $689(41)$ & $243(35)$ & $446(65)$ \\
\hline College graduate & $429(26)$ & $151(35)$ & $278(65)$ \\
\hline Postgraduate & 317 (19) & $95(30)$ & $222(70)$ \\
\hline \multicolumn{4}{|l|}{$\begin{array}{l}\text { Respondent's marital } \\
\text { status }\end{array}$} \\
\hline Single & $164(10)$ & $64(39)$ & $100(61)$ \\
\hline Married & $1284(77)$ & $430(33)$ & $854(67)$ \\
\hline Living as married & $102(6)$ & $42(41)$ & $60(59)$ \\
\hline $\begin{array}{l}\text { Divorced, separated, } \\
\text { or widowed }\end{array}$ & $121(7)$ & $43(36)$ & $78(64)$ \\
\hline \multicolumn{4}{|l|}{$\begin{array}{l}\text { Number of children in } \\
\text { household }\end{array}$} \\
\hline 1 & $468(28)$ & $171(37)$ & $297(63)$ \\
\hline 2 & $737(44)$ & $260(35)$ & $477(65)$ \\
\hline$\geqslant 3$ & $467(28)$ & $148(32)$ & $319(68)$ \\
\hline \multicolumn{4}{|l|}{$\begin{array}{l}\text { Household income } \\
\text { (thousands \$) }\end{array}$} \\
\hline$<50$ & $686(43)$ & $259(38)$ & $427(62)$ \\
\hline $50-74$ & $457(28)$ & $140(31)$ & $317(69)$ \\
\hline$\geqslant 75$ & $461(29)$ & 155 (34) & $306(66)$ \\
\hline
\end{tabular}

usable date for $93 \%$ of recalled injuries. Some injuries close to 365 days in the past might have been remembered as being more than 365 days in the past and therefore were not reported to us at all, as we asked about injuries only in the past year; if this occurred, our analysis would find a shorter time from interview to reported injury date compared with the time from interview to medical visit date, even if there were no actual difference in the two time intervals. Therefore we repeated this analysis using only injury visits that occurred within the most recent 300 days, as even injuries remembered as being somewhat further in the past might still be recalled as being within the past year.

Two adults reported information about more than one child in the same family. There were 193 (12\%) children with two or three new injuries with a medical visit. We used a family identifier and a robust (sandwich) variance estimator to relax the assumption that outcomes within the same family were independent. ${ }^{9}$ We used Stata statistical software. $^{10}$ 


\begin{tabular}{|c|c|c|c|}
\hline Characteristic & $\begin{array}{l}\text { Total }(n=1896 \text { ) } \\
\text { No (column \%) }\end{array}$ & $\begin{array}{l}\text { Respondent } \\
\text { did not recall } \\
\text { injury }(n=746) \\
\text { No (row \%) }\end{array}$ & $\begin{array}{l}\text { Respondent } \\
\text { did recall } \\
\text { injury } \\
\text { ( } n=1150) \\
\text { No (row \%) }\end{array}$ \\
\hline \multicolumn{4}{|l|}{ Place of treatment } \\
\hline Clinic & $885(47)$ & $455(51)$ & 430 (49) \\
\hline Urgent care & 715 (38) & $210(29)$ & 505 (71) \\
\hline $\begin{array}{l}\text { Emergency } \\
\text { department }\end{array}$ & 232 (12) & $58(25)$ & $174(75)$ \\
\hline Hospital outpatient & 41 (2) & $12(29)$ & 29 (71) \\
\hline Hospital inpatient & $23(1)$ & $11(48)$ & $12(52)$ \\
\hline \multicolumn{4}{|l|}{ Type of injury } \\
\hline Brain, internal & $24(1)$ & $11(46)$ & $13(54)$ \\
\hline Fracture & 216 (11) & 35 (16) & $181(84)$ \\
\hline Burn & $101(5)$ & $30(30)$ & $71(70)$ \\
\hline Total, major & 341 (18) & $76(22)$ & $265(78)$ \\
\hline Open wound & $565(30)$ & $143(25)$ & $422(75)$ \\
\hline Bruise, crush & 778 (41) & $449(58)$ & 329 (42) \\
\hline Sprain & $212(11)$ & 78 (37) & $134(63)$ \\
\hline Total, minor & 1555 (82) & $670(43)$ & $885(57)$ \\
\hline
\end{tabular}

\section{RESULTS}

\section{Description}

Mean age of the 1672 injured children was 3.5 years and 56\% were male (table 1). For $97 \%$ of the children the respondent was a birth parent. Mean adult respondent age was 34 years, $45 \%$ finished college, and $77 \%$ were married. Households had from one to nine children with a mean of 2.2. Most households (57\%) earned over $\$ 50$ thousand dollars a year.

The count of the three most recent injuries for the 1672 children was 1896. Nearly half of these injuries involved only a clinic visit, $38 \%$ were treated in urgent care, $12 \%$ were treated in an emergency department, and 3\% had a hospital outpatient visit or inpatient stay (table 2). Most injuries $(82 \%)$ were classified as minor.

\section{Recall of any new injury}

Almost two thirds of the respondents reported at least one child injury with a medical visit in the past year: 1093/ $1672=0.65$ (95\% CI 0.63 to 0.68$)$. Using information about the three most recent injuries, adults reported 1220 separate child injuries with a medical visit in the year before interview (table 3). In the utilization data there were 1477 children with one injury in the previous year, 166 with two injuries, and 29 with three or more injuries, for a total of 1896 new first, second, or third injuries. The rate ratio of reported to observed injuries was $1220 / 1896=0.64$ (95\% CI 0.61 to 0.68 ).

\section{Variation in recall with time}

Using information about up to three new injuries in the year before the interview, the proportion of injuries recalled was $1150 / 1896=0.61$; this was less than the rate ratio of 1220 / $1896=0.64$ for injury counts in table 3 , because table 3 included 70 reported second or third injuries that had no corresponding new second or third injury in the utilization data. The smoothed plot (fig l) of recall by time since injury visit estimated the proportion recalled as 0.82 (95\% CI 0.79 to 0.85 ) at time 0 and 0.37 (95\% CI 0.32 to 0.41$)$ at time 365 days.

Recall varied by place of treatment and whether the injury was minor or not (fig 2). Both variables were related to recall: $p<0.001$ for tests of main effects terms. However there was little evidence that the change in recall with time varied with these terms. Model fit was best when interactions were
Table 3 Counts for 1672 children according to the number of injuries in the previous year: reported number of injuries with a medical visit and new injuries from medical utilization data

\begin{tabular}{lll}
\hline No of injuries & $\begin{array}{l}\text { Reported medical } \\
\text { visit }\end{array}$ & $\begin{array}{l}\text { Injury visit in } \\
\text { utilization data }\end{array}$ \\
\hline 0 & 577 & 0 \\
1 & 983 & 1477 \\
2 & 99 & 166 \\
3 & 13 & 25 \\
4 & $*$ & 2 \\
5 & $*$ & 2 \\
6 & $*$ & 0 \\
Total children & 1672 & 1672 \\
Total injuries & 1220 & 1902 \\
\hline
\end{tabular}

*Questions were not asked about more than three new injuries with a medical visit.

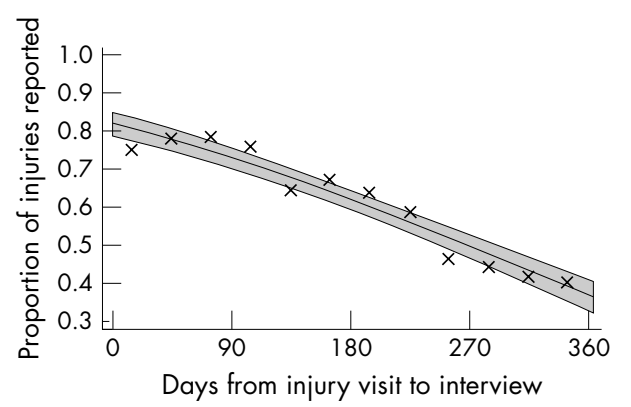

Figure 1 Plot of the proportion of child injuries with a medical visit recalled by a parent according to days since the first visit for each injury. The line is from logistic regression with shaded pointwise confidence intervals. The $\mathrm{X}$ symbols are the actual proportions for each month of the data.

allowed between treatment place and injury severity, and major injuries were grouped together, regardless of treatment place.

There was little evidence that recall varied by child age, child sex, respondent's age, respondent's marital status, number of children in the home, or yearly household income. There was evidence that recall was better if the adult respondent had more years of education $(p=0.02)$, but that association made so little difference to the plots in fig 2 that we do not present those results.

Using the plots of fig 2, we created estimates of the proportion of injuries recalled for time from injury to interview of $0,15,46,91,137,183$, and 365 days. The estimates for 0 and 365 days are for the ends of the plotted curves. The other times correspond to points on the curves that estimate the recalled proportions if respondents were asked about injuries in the previous one, three, six, nine, or 12 months (table 4).

\section{Recall of injury date}

Among the 1068 recalled injuries with a reported injury date, the mean reported time from interview to injury was 154 days and the mean time from interview to visit in the utilization data was 157 days: mean difference -4 days (95\% CI -8 to +1$)$. Limiting this analysis to 935 injuries within 300 days of interview in the utilization data, the respective mean times were 135 days and 132 days: mean difference +2 days $(95 \%$ CI -2 to +6$)$.

\section{DISCUSSION}

Parents could recall $61 \%$ of the injuries to their young child that were in computerized medical records in the previous 


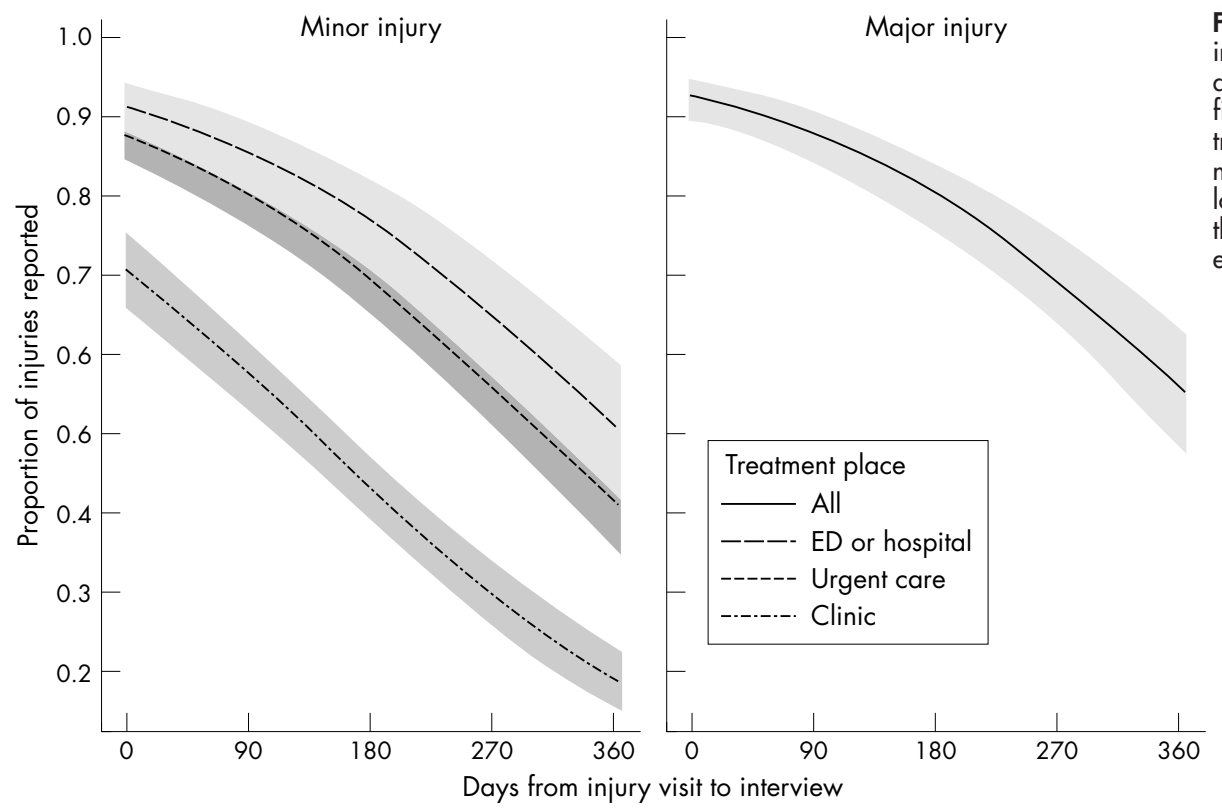

Figure 2 Plot of the proportion of child injuries with a medical visit recalled by a parent according to the days since the first visit for each injury, the place of treatment, and whether the injury was major or minor. Proportions are from logistic regression. Shaded areas cover the pointwise confidence intervals for each line (ED, emergency department).

year. About $80 \%$ of all major injuries treated in the previous year were recalled. Recall was intermediate, $70 \%$ to $77 \%$, for minor injuries treated in urgent care, an emergency department, or a hospital. Recall was worst, $43 \%$, for minor injuries treated only in a clinic.

A limitation of our study is that there could be errors in the computerized utilization data. Some children might have visit codes for an injury when the actual visit was for a non-injury problem. Studies of Group Health automated data, compared with written medical records, reveal some errors, but a generally high degree of accuracy. ${ }^{11-13}$

There might also be errors in our method of determining which visits represented a new injury. However, $71 \%$ of the children had only one injury with a medical visit in the previous year and $87 \%$ had only one or two such injuries. Therefore misclassification regarding a new injury date or the presence of a new injury would affect only a small portion of our data.

Reporting an injury and recall of an injury are not the same. Some parents may have recalled an injury, but chose not to report it in the telephone interview. It is possible that different questions might have revealed additional injuries.

Only $66 \%$ of eligible parents agreed to participate in the study. Our results best reflect what cooperative parents voluntarily reported after consent using our study questions.

Cash and Moss studied the recall of 377 persons who were in a motor vehicle crash in 1966-67 in North Carolina and were classified as injured on the police report. ${ }^{14}$ If the crash was within three months of the interview, 99\% of subjects recalled a crash and $87 \%$ (95\% CI $77 \%$ to $94 \%$ ) reported an injury. If the crash was nine to 12 months in the past $78 \%$ recalled a crash and $63 \%$ (95\% CI 52\% to $73 \%$ ) reported an injury. Overall recall of an injury for a one year interval was $75 \%$ (95\% CI $70 \%$ to $79 \%$ ). Injuries with bleeding or limb distortion were more likely to be reported compared with less obvious injuries. The overall reporting of injuries in the study by Cash and Moss was similar to what we found for our intermediate recall group.

Harel et al analyzed data from the 1988 National Health Interview Survey regarding injuries to children. ${ }^{15}$ Adults were asked to recall the injuries of their children that involved a medical visit. For children $0-4$ years, the reported injury rate based on a one month recall period was 27 per 100 childyears and the rate for a 12 month recall period was 12 . In Harel's study, as in ours, recall declined less steeply for more severe injuries and injuries involving a hospitalization.

Mock et al conducted a survey in Ghana and analyzed 1534 injuries reported by 21105 respondents. ${ }^{16}$ For 2537 children age $0-4$ years, the rate based upon a recall period of one month was 24.3 per 100 person-years, compared with 6.1 for a 12 month recall period, a $75 \%$ decline in reported incidence.

When rates from one month recall intervals were compared with rates from 12 month intervals, the decline in reported injury incidence was 56\% in the National Health Interview Survey ${ }^{15}$ and $75 \%$ in the survey from Ghana. ${ }^{16}$ These declines were steeper than the change in proportion of injuries

Table 4 Proportion $(95 \% \mathrm{Cl})$ of injuries recalled by months since first visit for each new injury, whether injury was minor or major, and place of injury treatment for minor injuries

\begin{tabular}{|c|c|c|c|c|}
\hline Months & $\begin{array}{l}\text { Minor: clinic } \\
(n=756 ; 40 \%)\end{array}$ & $\begin{array}{l}\text { Minor: urgent care } \\
(\mathbf{n}=597 ; 31 \%)\end{array}$ & $\begin{array}{l}\text { Minor: ED* or hospital } \\
(n=202 ; 11 \%)\end{array}$ & $\begin{array}{l}\text { Major: all places } \\
(\mathrm{n}=341 ; 18 \%)\end{array}$ \\
\hline 0 & 0.71 (0.66 to 0.76$)$ & $0.88(0.85$ to 0.91$)$ & $0.92(0.88$ to 0.94$)$ & 0.93 (0.91 to 0.95$)$ \\
\hline 0.5 & $0.69(0.64$ to 0.74$)$ & $0.87(0.84$ to 0.90$)$ & $0.91(0.87$ to 0.94$)$ & 0.93 (0.90 to 0.94$)$ \\
\hline 1.5 & 0.65 (0.60 to 0.69$)$ & 0.85 (0.82 to 0.88$)$ & 0.89 (0.85 to 0.92$)$ & 0.91 (0.88 to 0.93$)$ \\
\hline 3 & $0.58(0.53$ to 0.62$)$ & $0.81(0.77$ to 0.84$)$ & $0.86(0.81$ to 0.90$)$ & 0.88 (0.85 to 0.91$)$ \\
\hline 4.5 & $0.50(0.46$ to 0.54$)$ & $0.76(0.72$ to 0.79$)$ & $0.82(0.77$ to 0.86$)$ & 0.85 (0.81 to 0.88$)$ \\
\hline 6 & 0.43 (0.39 to 0.47$)$ & $0.70(0.65$ to 0.73$)$ & $0.77(0.71$ to 0.82$)$ & 0.80 (0.76 to 0.84 ) \\
\hline 12 & $0.19(0.15$ to 0.23$)$ & $0.41(0.35$ to 0.47$)$ & $0.51(0.42$ to 0.59$)$ & 0.56 (0.48 to 0.63 ) \\
\hline
\end{tabular}




\section{Key points}

- It is not known how accurately parents can recall the injuries of their children younger than 6 years.

- We found that parent recall of the injuries of their children decreased with time from injury to interview.

- Recall was best for major injuries: brain or internal injuries, fractures, dislocations, and burns.

- Recall was intermediate for minor injuries treated at a hospital, emergency department, or urgent care clinic.

- Recall was worst for minor injuries treated in a clinic office.

recalled in our data for the same recall periods (19\%) (fig 1). They were also steeper than the $12 \%$ decline reported by the North Carolina crash study, ${ }^{14}$ comparing three month recall with 12 month recall intervals. All four studies offered evidence that recall decays more steeply for less serious injuries. It is possible that the average injury and its surrounding events were more severe and easier to recall in our study and the North Carolina crash study, compared with the other two studies.

Another possible reason for the observed differences between the studies is that the National Health Interview Study ${ }^{15}$ and the study from Ghana ${ }^{16}$ relied on two pieces of information: recall of an injury and recall of the approximate date for that injury. Recall would appear to decline more quickly if people reported many injuries as occurring more recently than they actually did, a phenomenon called telescoping. ${ }^{15}$ However, we found little evidence of telescoping: the mean reported time from interview to injury was similar to the mean time from interview to the first visit for each injury in the computerized utilization data.

Our results suggest that a six month recall period can be used to identify nearly $90 \%$ of major injuries. For minor injuries treated in a hospital, emergency department, or urgent care center, a three month recall period can identify almost $90 \%$ of the injuries. For minor injuries treated in a clinic, even the shortest recall periods may identify fewer than $70 \%$ of the injuries.

\section{ACKNOWLEDGEMENTS}

The authors thank the following Group Health staff for their contributions to this study: Julia Anderson, Virginia Immanuel, Cynthia Sisk, Margaret Farrell-Ross, Darren Malais, Minqui Jiang, Dr David Carrell, and Eve Adams.

\section{Authors' affiliations}

P Cummings, Harborview Injury Prevention and Research Center and the Department of Epidemiology, School of Public Health and Community Medicine, University of Washington, Seattle, Washington State, USA

F P Rivara, Harborview Injury Prevention and Research Center and the Department of Pediatrics, School of Medicine, University of Washington, Seattle, Washington State, USA

R S Thompson, R J Reid, Group Health Cooperative, Department of Preventive Care and the Center for Health Studies, Seattle, Washington State, USA

Funding for this study resulted from Interagency Agreement \#Y1-HD2346 between the National Institute of Child Health and Human Development and the National Center for Injury Prevention and Control, Centers for Disease Control and Prevention, with assistance from a cooperative agreement between CDC and the Association of Schools of Public Health, grant number S2245- 22/22.

\section{REFERENCES}

1 Branum AM, Collman GW, Correa A, et al. The National Children's Study of environmental effects on child health and development. Environ Health Perspect 2003;111:642-6.

2 National Center for Health Statistics. International classification of diseases, 9th revision, clinical modification (ICD-9-CM). Washington, DC: DHHS Publication No (PHS), 91-1260.

3 American Association for Public Opinion Research. Standard definitions: final dispositions of case codes and outcome rates for surveys. 3rd Ed. Lenexa, KS: American Association for Public Opinion Research, 2004.

4 Hosmer DW, Lemeshow S. Applied logistic regression. 2nd Ed. New York: John Wiley \& Sons, 2000.

5 Harrell FE Jr. Regression modeling strategies: with applications to linear models, logistic regression, and survival analysis. New York: Springer-Verlag, 2001:183-4.

6 Royston P, Altman DG. Regression using fractional polynomials of continuous covariates: parsimonious parametric modelling (with discussion). Applied Statistics 1994;43:429-67.

7 Sauerbrei W, Royston P. Building multivariable prognostic and diagnostic models: transformation of the predictors by using fractional polynomials. J R Stat Soc A 1999;162:71-94.

8 Hastie TJ, Tibshirani RJ. Generalized additive models. London: Chapman \& Hall, 1990 .

9 Hardin J, Hilbe J. Generalized linear models and extensions. College Station, TX: Stata Press, 2001.

10 Stata Corporation. Stata statistical software: release 8.2. College Station, TX: Stata Corporation, 2003.

11 Newton KM, Wagner EH, Ramsey SD, et al. The use of automated data to identify complications and comorbidities of diabetes: a validation study. J Clin Epidemiol 1999;52:199-207.

12 Mullooly J, Drew L, DeStefano F, et al. Quality of HMO vaccination databases used to monitor childhood vaccine safety. Vaccine Safety DataLink Team. Am J Epidemiol 1999;149:186-94.

13 Barlow WE, Davis RL, Glasser JW, et al. The risk of seizures after receipt of whole-cell pertussis or measles, mumps, and rubella vaccine. N Engl J Med 2001;345:656-61.

14 Cash WS, Moss AJ. Optimum recall period for reporting persons injured in motor vehicle accidents. Vital Health Stat 1 1972;2:1-33.

15 Harel Y, Overpeck MD, Jones DH, et al. The effects of recall on estimating annual nonfatal injury rates for children and adolescents. Am J Public Health 1994;84:599-605

16 Mock C, Acheampong F, Adjei S, et al. The effect of recall on estimation of incidence rates for injury in Ghana. Int J Epidemiol 1999;28:750-5. 